\title{
Um Exemplo de Análise Contrastiva: O grafema r/rrr em português e italiano*
}

Lúcia Fulgêncio

Patrizia Bastianetto**

\begin{abstract}
RESUMO: Neste trabalho é apresentado um exemplo de análise contrastiva entre a língua italiana e o português falado no Brasil, do ponto de vista fonético. Tomam-se os sons grafados $<\mathrm{r}>$ ou $<\mathrm{rr}>\mathrm{e}$ examinam-se as suas possibilidades de realização fonética em cada língua, individualmente, identificando o contexto de produção de cada realização fonológica.

Posteriormente, comparam-se os sistemas fonológicos das duas línguas quanto a esse aspecto, indicando os ambientes de simetria ou dissimetria estrutural. A evidenciação dos ambientes onde ocorre dissimetria na realização de $<\mathrm{r}>/<\mathrm{rr}>$ pode ser útil para o professor de italiano para brasileiros (ou vice-versa), já que provavelmente esses ambientes constituirão pontos de maior dificuldade na aprendizagem da produção desses sons.
\end{abstract}

\section{Introdução}

Quando um indivíduo se expressa através de uma língua estrangeira, é comum que se verifiquem problemas de interferência da língua materna na sua comunicação. No processo de aprendizagem e de utilização de uma $\mathrm{L}_{2}$, o falante estrangeiro tem a tendência intuitiva de se apoiar na língua materna como ponto de referência lingüístico 
e, por esse motivo, eventualmente comete desvios na produção em $\mathrm{L}_{2}$, ao construir estruturas baseadas no padrão da sua língua materna.

Por exemplo, quando um inglês fala português sem flexionar os verbos, ou quando um italiano não coloca o sufixo $-s$ no plural dos nomes, ou quando um francês desloca o acento tônico para a última sílaba das palavras, todos eles estão agindo assim por estarem sofrendo a interferência da sua língua materna na produção do português: em inglês, geralmente os verbos não se flexionam em número e pessoa; em italiano, não se usa o sufixo $-s$ na formação do plural; e, em francês, todas as palavras são oxítonas, diferentemente do que ocorre no português.

Essa interferência da língua materna na língua estrangeira é bastante comum, e é responsável por algumas das dificuldades na aprendizagem de uma segunda língua. As dissimetrias entre as estruturas da língua materna e da $\mathrm{L}_{2}$ constituem, portanto, um ponto de especial interesse para o professor de língua estrangeira.

Um dos aspectos em que essa interferência é identificada de forma mais evidente é na pronúncia. Quantas vezes já vimos um estrangeiro que fala bastante bem nossa língua, mas não consegue se desvencilhar de uma certa dose de sotaque. Evidentemente, esse sotaque tem como base a pronúncia da língua materna, ou seja, é decorrente de uma espécie de "contaminação" tanto dos fonemas existentes na sua própria língua, quanto da forma com que o falante está acostumado a articular esses sons em contexto (isto é, das regras fonológicas que operam na $L_{1}$ ).

$\mathrm{Na}$ língua italiana, um dos casos onde há uma dissimetria no sistema fonológico comparativamente ao português, implicando em problemas de pronúncia, é o que acontece na produção dos sons grafados $r$ ou $r r$.

Acrescente-se ainda o fato de haver várias palavras homógrafas nas duas línguas, mas que nem por isso são necessariamente homófonas (por exemplo, é o caso de ferro, remo, arco, bar). 
Este trabalho tem então o objetivo de examinar os tipos de realização dos sons grafados $r / r r$ em italiano e em português e, através de uma análise contrastiva, comparar os sistemas fonológicos das duas línguas quanto a esse aspecto. A partir desse confronto poderão ser evidenciadas as diferenças e as similaridades dos sons grafados $r$ I $r r$ nas duas línguas, tornando possível determinar quais situações específicas poderiam constituir pontos de dificuldade na produção desses sons, tanto para o aprendiz brasileiro que estuda italiano, quanto para o italiano que aprende o português do Brasil.

Considerando as diferenças internas que uma língua apresenta, tais como a variação diatópica (ou seja, as variantes regionais e os falares locais) e a variação diastrática (que consiste na utilização de uma ou outra forma expressiva em função do nível sócio-cultural diferente dos falantes), delimitaremos, neste trabalho, para as avaliações relativas à realização fonética, os seguintes modelos: para a língua portuguesa do Brasil, a pronúncia do estado de Minas Gerais e, mais especificamente, a da região urbana central (língua materna de uma das autoras), que representa a pronúncia padrão em grande parte coincidente com a utilizada pela maioria dos meios de comunicação; para a língua italiana, será considerada a pronúncia dita "standard" ou padrão (utilizada por uma das autoras enquanto falante nativa de italiano). Essa pronúncia, apresentada no dicionário da língua italiana Zingarelli (1989), corresponde ao modelo apresentado ao estudante estrangeiro de língua italiana e é o padrão geralmente utilizado em todo o território nacional pelos meios oficiais de comunicação.

\section{Realização dos sons grafados $r / r r$ em italiano}

Em italiano, tanto os sons grafados $r$ quanto os grafados $r r$ pertencem à categoria das consoantes vibrantes (simples ou múltipla).

BATINTI (1993 : 23) analisou o sistema consonantal da língua italiana através de uma amostra de 53.422 fonemas, que constituem 6.889 palavras do léxico básico da língua italiana. Dessa pesquisa 
resultou que as vibrantes constituem $9.69 \%$ do conjunto consonantal, incluindo a vibrante simples e a vibrante múltipla.

Em italiano, como dissemos, os sons grafados $r$ / $r r$ são sempre vibrantes. Na pronúncia padrão, a vibrante é apical e alveolar, ou seja, sua realização acontece através de uma ou mais batidas da ponta da língua (ápice) contra os alvéolos. Pode ocorrer também, por características individuais, a vibrante uvular (mais comum no norte e no centro da Itália (cf. CANEPARI, 1992 : 85-86).

Em italiano "standard" existe uma oposição fonologicamente distintiva entre a vibrante simples e a vibrante múltipla. Por exemplo, na palavra italiana caro o $r$ é pronunciado como uma vibrante simples: ['ka:řo] ; e na palavra carro o grupo grafado $r r$ é pronuñciado como uma vibrante múltipla: ['karô]].

Alguns autores consideram que há, em italiano, um único fonema $/ r /$, que seria reduplicado no caso da realização como vibrante múltipla (esta é a posição adotada, por exemplo, por CANEPARI, 1992 : 84). Outros lingüistas (cf. BIAGI, 1985 : 232) consideram que há, nesse caso, dois fonemas distintos, uma vez que existem pares de vocábulos de significado diferente (como caro e carro) que se opõem unicamente pelo tipo de vibrante (ou seja, pelo traço da duração consonantal). Aqui não entraremos no mérito dessa questão e simplesmente adotaremos a análise de Canepari, dado que o que interessa é que há (sem dúvida) oposição fonológica entre a vibrante de caro e a de carro.

Em português (no dialeto aqui considerado), por outro lado, não há realização fonética de vibrante múltipla e, sendo assim, evidentemente não existe oposição fonologicamente distintiva entre a vibrante simples e a vibrante múltipla ( tal distinção, no entanto, pode ocorrer em outros dialetos, como no sul do país). 
Vejamos, como exemplificação, o quadro abaixo, que apresenta os ambientes da língua italiana em que pode ocorrer a vibrante simples (que aqui será representada por /r/) e a vibrante múltipla (que aqui será representada por $/ \mathrm{rr} /$ ).

QUADRO 1

REALIZACẼOO DOS SONS GRAFADOS $R / R R$ EM ITALIANO

Vibrante simples

\begin{tabular}{|c|c|c|c|c|c|c|}
\hline$\#_{-}$ & $V_{-} \mathrm{V}$ & $C_{-} \mathrm{V}$ & ${ }_{-} \mathrm{C}$ & \# & $\# V$ & $\# \mathrm{C}$ \\
\hline $\begin{array}{l}\text { remoto } \\
\text { /re'noto/ }\end{array}$ & $\begin{array}{c}\text { caro } \\
\text { /karo/ } \\
\text { Mauro } \\
\text { /'mawro/ }\end{array}$ & $\begin{array}{l}\text { prego } \\
\text { fprego/ }\end{array}$ & $\begin{array}{c}\text { parte } \\
\text { /parte/ }\end{array}$ & $\begin{array}{c}\text { bar } \\
\text { /"bar/ }\end{array}$ & $\begin{array}{l}\text { perora } \\
\text { /pe'roral }\end{array}$ & $\begin{array}{l}\text { per caso } \\
\text { /per'kazo/ }\end{array}$ \\
\hline
\end{tabular}

Vibrante múltipla

\begin{tabular}{c|c|c|c|c|c|c}
\hline$\#_{-}$ & $\mathrm{V}_{-} \mathrm{V}$ & $\mathrm{C}_{-} \mathrm{V}$ & $\mathrm{C}_{-}$ & $-^{\#}$ & - \#V & - \#C \\
\hline & $\begin{array}{c}\text { carro } \\
\text { fkarrol }\end{array}$ & & & & &
\end{tabular}

\section{LEGENDA :}

$/ \mathrm{r} /$ : vibrante simples

/rr/ : vibrante múltipla

Analisando o quadro acima vemos que a vibrante simples / $\mathrm{r} /$ pode se realizar em qualquer contexto onde pode ocorrer consoante: em posição inicial de palavra (\#), em posição medial intervocálica 
(V_V), em posição medial precedida de consoante e seguida de vogal (C_- V), antes de consoante (_C), em posição final absoluta (_\#), ou em posição final seguida de vogal ou consoante ( $\# \mathrm{~V}$, \#C). Acrescente-se ainda a realização da vibrante simples / $\mathrm{r}$ / entre vogal assilábica e vogal (como, por exemplo, em Mauro / 'mawro/).

Já a vibrante múltipla $/ \mathrm{rr} /$ realiza-se exclusivamente em posição intervocálica. Em termos fonéticos, é também possível a ocorrência da vibrante múltipla em limite de palavra, quando a primeira termina em $/ \mathrm{r} /$ e a seguinte inicia-se com $/ \mathrm{r} /$ (como, por exemplo, em per rimuovere [perii'mws:vere]), ou em início de palavra, quando ocorre o chamado raddoppiamento sintattico ${ }^{1}$ (como, por exemplo, em arrivo a Roma [a'ri:voa'ro:ma]); no entanto, nesses casos não há contraste fonologicamente distintivo.

A presença da vibrante múltipla /rr/ (foneticamente [ $\tilde{\mathrm{r}}]$ ) em carro e em erra, por exemplo, em oposição à vibrante simples $/ \mathrm{r} /$ (foneticamente $[\breve{r}]$ ) em caro e em era, define pares de vocábulos distintos. Tal contraste só é fonologicamente significativo em posição intervocálica.

Como vimos, a vibrante $/ \mathrm{r} /$ (como também outras consoantes do sistema fonológico do italiano) pode se realizar como breve (ou simples) - que, no caso de $/ \mathrm{r} /$, é chamada de vibrante simples - ou então longa (ou tensa ou dupla) - no caso de/rr/, chamada de vibrante múltipla (cf. DARDANO, $1991: 193-194$ ). Uma consoante longa diferencia-se pela sua maior duração comparativamente à consoante breve e tem, geralmente, uma tensão maior e uma duração de aproxi-

\footnotetext{
${ }^{1}$ Raddoppiamento sintattico é o nome dado ao processo que implica numa maior duração da pronúncia da consoante inicial de palavra, quando precedida por palavra que acaba com vogal, como por exemplo em pii rapido [pyu'ră:pido], sto bene [stbb:e:ne], da noi [da'n:o:y] (cf. CANEPARI, 1986:27-28). O raddoppiamento (ou rafforzamento) sintattico não se verilica sistematicamente sempre quando há condições para a sua aplicação, e pode não ocorrer por diversos motivos, como por exemplo em decorrência de preferências individuais, em registros mais formais, por questões de ênfase, e em sílabas consideradas "complexas" ou "complicadas" para o falante, o que dá um caráter variável à aplicação desse fenômeno (cf. CANEPARI, 1986:210).
} 
madamente $100 \%$ a mais em relação à duração da consoante breve ${ }^{2}$ (veja-se, a esse respeito, a Figura 1).

No latim a duração das vogais tinha relevância fonológica, exercendo papel distintivo (como por exemplo em věnit (vem) vēnit (veio)); essa função perdeu-se no italiano, mas o traço "duração" continua sendo fonologicamente distintivo no caso de algumas consoantes.

$\mathrm{Na}$ língua italiana a oposição entre consoantes breves versus consoantes longas é de grande importância, na medida em que define pares de vocábulos diferentes. Por exemplo, caro /'karo/ carro / 'karro/, ala /'ala/ alla /'alla/, vano /'vano/ vanno r/'vanno/, eco / 'eko/ ecco /'ekko/ são pares mínimos que se distinguem exclusivamente pelo traço da duração consonantal; ou seja, cada palavra do par tem um significado diferente devido à presença de uma consoante breve ou longa.

Além disso, há também uma diferença na duração da vogal acentuada: em italiano, a vogal tônica medial é sempre mais longa do que as demais, exceto se seguida de consoante longa (por exemplo, caro ['ka:r̆o] carro ['kar̃o], vano ['va:no] vanno ['van:o]). Entretanto, esse traço é automático (isto é, é resultado de uma regra fonológica) e não é distintivo, apesar de ser observável foneticamente (cf. CANEPARI, $1986: 25$ ).

Apresentamos a seguir o gráfico de um teste realizado no Laboratório de Fonética da FALE/UFMG, onde se podem verificar dados relativos à duração da vibrante simples ou múltipla, bem como da vogal tônica que a precede. Para esse registro foi utilizada uma fita cassete que contém modelos de pronúncia do italiano, e que integra a obra de CANEPARI, 1986.

${ }^{2}$ A vibrante longa / $\mathrm{r} /$ e outras consoantes longas do italiano são também chamadas de "geminadas" ou sũo entendidas como o resultado de um processo de reduplicação (denominado em italiano raddoppiamento). 
FIGURA 1

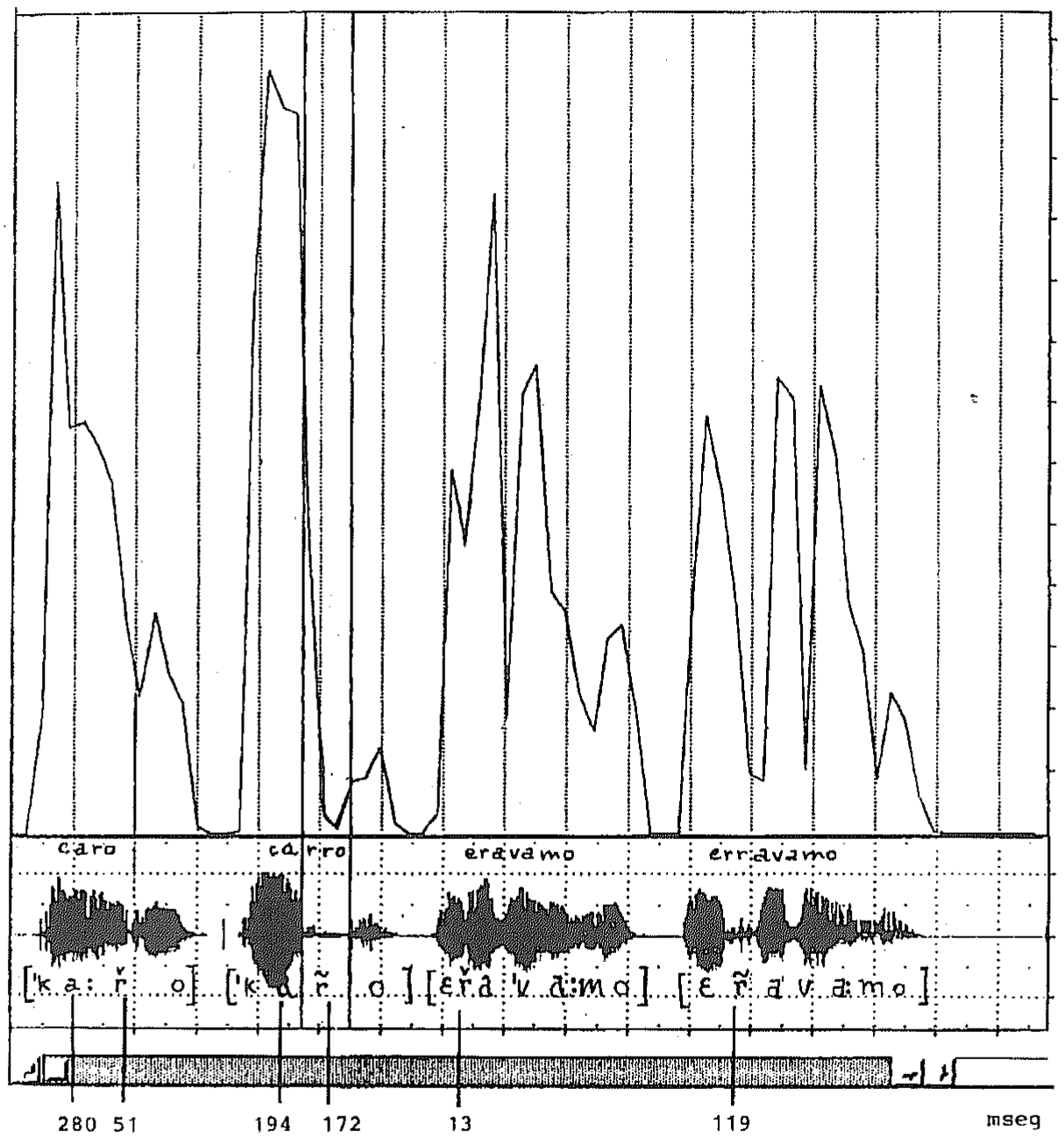


Observando a figura 1, podemos confirmar que a vibrante múltipla é uma consoante de duração bastante mais longa comparativamente à vibrante simples (172 milissegundos em carro e $51 \mathrm{mseg}$. em caro; $119 \mathrm{mseg}$. em erravamo e $13 \mathrm{mseg}$. em eravamo). Além disso, a vogal tônica que precede a vibrante múltipla (consoante longa) tem uma duração menor do que a que precede a vibrante simples (194 mseg. em carro e $280 \mathrm{mseg}$. em caro).

O traço da duração consonantal é um aspecto especialmente interessante em um estudo de fonologia contrastiva italiano/português, dado que na língua portuguesa esse é um traço inexistente, e portanto de dificil percepção e produção para um estudante brasileiro.

\section{Realização dos sons grafados $r / r r$ em português}

Em português, os sons grafados $r / r r$ não são sempre vibrantes, como em italiano, mas podem também ser pronunciados como uma fricativa velar ou glotal, dependendo do contexto (como, por exemplo, em rato ['ha:tv] $)^{3}$.

No dialeto aqui considerado temos a vibrante simples alveolar [ aqui representadas por $/ R /$. Há ainda o caso da réalização $\emptyset$, em final de verbo, como mostrado a seguir.

Vejamos então o quadro abaixo, que apresenta os ambientes em que ocorrem esses sons em português.

\footnotetext{
${ }^{3}$ Além da vibrante simples e da fricativa velar ou glotal, existem ainda diversas variantes individuais e regionais dos sons grafados $r i r$, como a realização retroflexa (especialmente em algumas regiões do sul de Minas - como, por exemplo, na palavra porta ['p’:̣̂to]), a realização fricativa alveolar retroflexa (como em ar ['a:s ]), a vibrante alveolar múltipla (como em farra ['fa: $\left.\tilde{r}_{\text {a }}\right)$, e outras.

Além disso, alguns sons não grafados com $\mathrm{r} / \mathrm{rr}$, e que no dialeto padrão não são nem vibrantes nem fricativos, podem ser pronunciados, em outros dialetos, com o mesmo modo e ponto de articulação dos sons grafados r / rr: por exemplo, malvado [mar̆'va:du, mesmo ['me:hnvv], gente ['hẽ:t々].
} 
QUADRO 2

\section{REALIZACÃO DOS SONS GRAFADOS $R / R R$ EM PORTUGUÊS}

\begin{tabular}{|c|c|c|c|c|c|c|}
\hline \multirow[t]{2}{*}{ \#_ } & $V_{-} V$ & $\mathrm{C}_{-} \mathrm{V}$ & ${ }_{-} \mathrm{C}$ & _\# & $\# \mathrm{~V}$ & $\mathrm{HC}$ \\
\hline & $\begin{array}{l}\text { caro } \\
\text { /kard }\end{array}$ & $\begin{array}{c}\text { prato } \\
\text { /pratul }\end{array}$ & & & $\begin{array}{c}\text { mar alto } \\
\text { /ma'rawtu/ } \\
\text { comer o bolo } \\
\text { /ku'meru'bolu/ } \\
\text { ( / / ku'meu'bolu/) }\end{array}$ & $\approx$ \\
\hline
\end{tabular}

$\underline{Q}$

\begin{tabular}{c|c|c|c|c|c|c}
\hline$\#-$ & $\mathrm{V}_{-} \mathrm{V}$ & $\mathrm{C}-\mathrm{V}$ & $-\mathrm{C}$ & $-^{\#}$ & $\# \mathrm{~V}$ & - \#C \\
\hline & & & $\begin{array}{c}\text { comer } \\
\text { /ku'me/ }\end{array}$ & $\begin{array}{c}\text { comer obolo } \\
\text { /ku'meu'bolu/ } \\
(\sim / \text { ku'meru'bolu/ })\end{array}$ & $\begin{array}{c}\text { comer tudo } \\
/ \text { ku'me'tudu/ }\end{array}$ \\
\hline
\end{tabular}

Fricativa velar ou glotal

\begin{tabular}{|c|c|c|c|c|c|c|}
\hline$\#_{-}$ & $V_{-} V$ & C_V & C & _\# & \#V & \#C \\
\hline $\begin{array}{l}\text { rato } \\
\text { /'Ratu/ }\end{array}$ & $\begin{array}{l}\text { carro } \\
\text { /kaRu/ }\end{array}$ & & $\begin{array}{c}\text { arco } \\
\text { /aRku/ }\end{array}$ & $\begin{array}{c}m a r \\
/ \mathrm{maR}\end{array}$ & & $\begin{array}{l}\text { mar Morto } \\
\text { /maR'moRtul }\end{array}$ \\
\hline
\end{tabular}

\section{LEGENDA :}

$/ \mathrm{r} /$ : vibrante simples

$/ \mathrm{R} /$ : fricativa velar ou glotal 
A presença da fricativa /R/ em carro, em oposição à vibrante /r/ em caro, define pares de vocábulos distintos em português. Há, portanto, dois fonemas em português: / $\mathrm{r} / \mathrm{e} / \mathrm{R} /$. Tal contraste só ocorre em posição intervocálica (V_V); nos demais ambientes, /R/ e /r/ estão em distribuição complementar, conforme descrito a seguir.

Analisando o quadro acima, podemos agrupar da seguinte forma os ambientes em que ocorrem $/ \mathrm{r} / \mathrm{e} / \mathrm{R} /$ em português:

\section{1. $C_{-} V / \# \mathrm{~V}$}

Como segundo elemento de um grupo consonântico na mesma sílaba (C_V, como em prato /'pratu/ ou cru /'kru/), ou em final de palavra, seguida de palavra iniciada por vogal ( \#V, como em mar alto /ma'rawtu/, cor azul /kora'zuw/), ocorre sempre /r/ (vibrante simples ou "flap").

CÂMARA JR. (1970:50), ao analisar a sílaba, lembra que em português "há um fenômeno de ligação entre a sílaba final travada de um vocábulo e a vogal inicial de um vocábulo, que a ele se segue sem pausa". Dessa forma, em casos como mar alto /ma'rawtu/ e comer o bolo /ku'meru'bolu/, a consoante posvocálica em final de palavra - neste caso /r/ - liga-se à vogal da palavra imediatamente seguinte. Assim, a sílaba final, que era travada, torna-se uma sílaba livre, ao mesmo tempo que a sílaba seguinte ganha uma consoante prevocálica (por exemplo, mar alto /ma-'raw-tu/).

\section{V_V}

2.1. 1․ possibilidade: Em posição intervocálica, em palavras como caro /'karu/ ou para/'para/, ocorre a vibrante apical alveolar simples ou "flap" alveolar. Também entre ditongo e vogal ocorre /r/ (como, por exemplo, em Mauro /'mawru/).

2.2. 2 ${ }^{a}$ possibilidade : Em posição intervocálica pode ocorrer não só a vibrante (como descrito acima), mas também a fricativa $/ R /$, em palavras como em carro /'kaRu/ e farra /'faRa/.

No dialeto aqui considerado, o ponto de articulação pode variar entre a fricativa velar $[\mathrm{x}]$ e glotal [h]. Em outros dialetos, como no 
sulista, pode ocorrer nesse ambiente a vibrante múltipla ou trill [ $\tilde{\mathrm{r}}]$. Essa diferença de pronúncia implica somente numa variação a nível fonético.

Como já observamos, a presença de / $\mathrm{R} /$ em carro, em oposição a $/ \mathrm{r} /$ em caro, define pares de vocábulos diferentes, determinando dois fonemas distintos em português.

3. \#_,_C, \#, \#C

Ocorre sempre /R/ (fricativa velar ou glotal) nos seguintes ambientes: em posição inicial de palavra (como, por exemplo, em rato / 'Ratu/, rolo /'Rolu/, remo /'Remu/), antes de consoante (como, por exemplo, em porta /'poRta/, arma /'aRma/), em final de palavra (como em mar /'maR/, calor /ka'loR/), e em final de palavra seguida de palavra iniciada por consoante (como em mar Morto /maR'moRtu/, ar rarefeito /aRare'feytu/).

Também em início de sílaba, após uma consoante, tem-se /R/ (por exemplo, Israel /isRa' u/).

Se a palavra for um verbo, em posição final absoluta e em final de palavra seguida de vogal ou consoante pode ocorrer $\varnothing$ fonético (como, por exemplo, em comer [ku'me:]).

Nos ambientes_C, \# e \#C, existe a variante [ $\left[\begin{array}{c}r \\ v\end{array}\right]$ retroflexa, de ocorrência sobretudo na região ao sul de Minas Gerais, Goiás e oeste de São Paulo (como, por exemplo, em carne ['ka:r̆nı], amor [a'mor̆:], mar calmo [mar̆́n'ka:wmv]).

\section{4- Análise contrastiva dos sons grafados $r / r r$ no português e no italiano}

Nas línguas portuguesa e italiana, os sons grafados $r / r r$ terão, em determinados ambientes, pronúncias diferentes, conforme se pode verificar no quadro abaixo (nesta tabela são apresentadas palavras homógrafas, de forma a facilitar a comparação). 
QUADRO 3

ESTATUTO FONÉTICO-FONOLÓGICO DOS GRAFEMAS $R / R R$ NO PORTUGUÊS E NO ITALIANO

\begin{tabular}{|c|c|c|c|}
\hline & & \multicolumn{2}{|c|}{ Lingual } \\
\hline & & Portuguesa & Italiana \\
\hline Posicão & Exemplo & & \\
\hline $\begin{array}{l}\text { 1. C_V : depois de consoante, na } \\
\text { mesma sílaba }\end{array}$ & prato & $/ \mathrm{r} /$ & $/ \mathrm{r} /$ \\
\hline $\begin{array}{l}\text { 2. \#V : final de palavra, seguida } \\
\text { de palavra que começa com vogal }\end{array}$ & mar alto & $/ \mathrm{r} /$ & $/ \mathbf{r} /$ \\
\hline 3. V_V : intervocálica & $\begin{array}{l}\text { a) caro } \\
\text { b) carro }\end{array}$ & $\begin{array}{l}/ \mathrm{r} / \\
/ \mathrm{R} /\end{array}$ & $\begin{array}{l}/ \mathrm{r} / \\
/ \mathrm{rr} /\end{array}$ \\
\hline 4._C: antes de consoante & carne & $/ \mathrm{R} /$ & $/ \mathrm{r} /$ \\
\hline 5. \#_: inicial & remo & $/ \mathrm{R} /$ & $\mid \mathrm{r} /$ \\
\hline $\begin{array}{l}\text { 6. \# : final de palavra (exceto } \\
\text { verbos, em português) }\end{array}$ & bar & $/ \mathrm{R} /$ & $/ \mathrm{r} /$ \\
\hline $\begin{array}{l}\text { 7. \#C : final de palavra, seguida } \\
\text { de palavra que começa com } \\
\text { consoante (exceto verbos, em } \\
\text { português) }\end{array}$ & marMorto & $/ \mathrm{R} /$ & $/ \mathrm{r} /$ \\
\hline
\end{tabular}

\section{LEGENDA :}

$/ \mathrm{r} / \mathrm{r}$

$/ \mathrm{rr} / \quad$ :

/R $\quad:$

- realizado como vibrante simples [ $\breve{r}$ ]

realizado como vibrante múltipla $[\widetilde{\mathbf{r}}]$

realizado como fricativa velar $[\mathrm{x}]$ ou glotal [h]

${ }^{4}$ Como já vimos, em português, a consoante grafada $r$ no final de verbos tem geralmente realização fonética $\emptyset$; pode ser pronunciada alternativamente como vibrante simples $/ \mathrm{r} /$ se seguida de palavra que começa com vogal. 
Comparando os sistemas das línguas italiana e portuguesa, podemos definir os seguintes pontos de simetria ou de dissimetria com relação à produção dos sons grafados $r / r r$, e as suas conseqüências na aprendizagem :

1) Em italiano não existe a fricativa velar ou glotal, como em português. Em português, por outro lado, não existe a vibrante múltipla, como em italiano. Portanto, o brasileiro que aprende italiano ou vice-versa terá de aprender a articular um som que não existe no repertório fonológico da sua língua materna.

2) Tanto em italiano quanto em português existe a vibrante simples. No entanto, os ambientes em que esse som ocorre, nas duas línguas, nem sempre são os mesmos.

3) Há simetria entre os sistemas fonológicos do italiano e do português nos ambientes de números 1 e 2 listados acima $\left(\mathrm{C}_{-} \mathrm{V}\right.$ e \#V) - como prato /'prato/ em italiano e prato /'pratu/ em português, e mar alto /ma'ralto/ em italiano e mar alto /ma'rawtu/ em português : nesses contextos há sempre, nas duas línguas, a realização de vibrante simples.

4) Há dissimetria nos ambientes de números 4, 5, 6 e 7 ( C , \#_, \# e \#C) : nesses contextos a consoante grafada $r$ tem sempre um ponto e um modo de articulação diferentes em cada uma dessas línguas (como, por exemplo, em italiano carne /'karne/, remo /'remo/, bar /'bar/, mar Morto /mar'morto/, e em português carne / 'kaRni/, remo /'Remu/, bar /'baR/, mar Morto /maR'moRtu/).

5) Em posição intervocálica (número 3 do quadro), pode haver simetria ou dissimetria entre o português e o italiano, dependendo do caso. Há duas realizações possíveis para a consoante $r$, tanto em italiano quanto em português.

Uma dessas realizações, comum às duas línguas, é a vibrante simples, grafada sempre com um único $r$ tanto em italiano quanto em português (como em caro : /'karo/ em italiano, e /'karu/ em português). 
A outra realização, grafada $r r$ tanto em italiano quanto em português, varia ao compararmos cada uma dessas línguas: em italiano ocorre uma vibrante múltipla (como em carro /'karro/), e em português ocorre uma fricativa velar ou glotal (como em carro /'kaRu/). Portanto, no mesmo ambiente, ocorre uma dissimetria quanto ao modo e ao ponto de articulação da consoante.

6) Em italiano, o traço "duração" (presente no número 3 do quadro) é fonologicamente distintivo, o que não acontece em português.

É interessante notar que, em determinados ambientes, também em português existe a produção fonética de consoante longa. Por exemplo, em casos de haplologia, tem-se como resultado uma consoante longa (veja-se, a esse respeito, ALKIMIN e GOMES, 1982). Vejamos os exemplos abaixo:

\section{campo perigoso $\rightarrow$ ['kñp:iri'gozu] \\ litro de leite $\rightarrow$ ['lij:t'leyčl]}

Nesses casos há a produção fonética de uma consoante longa; mas pelo fato de ela não ser fonologicamente distintiva e não ser portadora de significado, o falante brasileiro não consegue nem mesmo perceber a sua produção.

Dessa forma, o brasileiro aprendiz de italiano terá então de conceber um novo traço fonológico (inexistente em português, mas distintivo em italiano), aprender a percebê-lo, a distingui-lo e a produzi-lo.

7) O falante de italiano, ao aprender o português, poderá utilizar como modelo de pronúncia $\mathrm{o} / \mathrm{r} /$ breve do italiano somente nas seguintes posições:

a) depois de consoante, com a qual forma uma sílaba (como, por exemplo, em português frango /'frãgu/);

b) em final de palavra seguida de palavra que começa com vogal (como em dor horrivel /doro'Rivew/); 
c) em posição intervocálica, quando ortograficamente a palavra é grafada com uma só consoante (como em farofa / fa'sfa/ ).

Em todas as outras posições ocorrerá sempre /R/, com articulação fricativa velar ou glotal, representando portanto dissimetria em relação ao italiano.

8) O falante de português, ao aprender o italiano, poderá utilizar como modelo de pronúncia o $/ \mathrm{r} /$ do português que se realiza em prato /'pratu/ e faro /'faru/, para todas as posições, com exceção da posição intervocálica, se ortograficamente a consoante é grafada $r r$ (como em italiano ferro /'ferro/). Nesse caso ocorrerá a vibrante múltipla, diferentemente portanto do que ocorre em português:

9) Em português, apesar de existir a vibrante simples como em italiano, ela nunca se realiza (no dialeto aqui considerado) nos casos de números 4, 5, 6 e 7, como em italiano - ou seja, nos ambientes \#_(início de palavra), _\# (final de palavra), \#C (final de palavra seguida de consoante) e _C (em posição médial, antes de consoante). Nesses casos, em português o fonema / $R /$ se realiza como fricativa velar ou glotal.

Além disso, em português não ocorre vibrante múltipla entre vogais (no dialeto aqui considerado), como acontece em italiano no número 3 do quadro.

São esses os contextos onde há dissimetria no sistema, e onde provavelmente haverá maior dificuldade do estudante brasileiro quanto à produção do fonema $/ \mathrm{r} / \mathrm{em}$ italiano. Portanto, são esses os ambientes onde o professor deve propor uma maior exercitação fonética.

Como vimos, a pronúncia do som grafado $r$ em italiano e e português nem sempre será um problema para o estudante estrangeiro, visto que há ambientes onde ocorre simetria entre os sistemas fonológicos dessas duas línguas: compare-se, por exemplo, a pronúncia do som grafado $r$ em palavras italianas como proprio/'proprio/ e lira/'lira/, e em palavras do português como proprio /'propriu/ e 
lira /'lira/, onde ocorre o mesmo ponto e modo de articulação dessa consoante.

No ensino do italiano a brasileiros, ou no ensino da língua portuguesa falada no Brasil a italianos, o professor deverá estar atento aos pontos de dissimetria do sistema fonológico dessas línguas quanto à produção dos sons grafados $r / r r$ aqui evidenciados: para o brasileiro que estuda italiano, sobretudo na produção de vibrante múltipla em posição intervocálica (como em burro), e na produção de vibrante simples nos ambientes_C (antes de consoante, como em carta), \#_ (em início de palavra, como em rapido), \# (em final de palavra, como em bar), \#C (em final de palavra seguida de palavra que começa com consoante, como em mar Morto); e para o italiano que estuda português, sobretudo na produção de fricativa velar ou glotal nesses mesmos ambientes.

Esses contextos onde ocorre dissimetria entre os sistemas fonológicos dessas duas línguas constituirão os pontos onde haverá, provavelmente, maiores dificuldades para o aprendiz na percepção e na produção desses sons.

PRESENTAZIONE: In questo studio si presenta un esempio di analisi contrastiva a livello fonetico tra la lingua italiana e quella portoghese parlata in Brasile. Per ognuna delle due lingue vengono analizzate le possibilità di realizzazione fonetica dei grafemi $<\mathrm{r}>0<\mathrm{rr}>$ definendo il contesto di ogni realizzazione fonologica.

In seguito sono comparati i sistemi fonologici dell'italiano e del portoghese per quanto concerne il tema proposto, evengono indicati gli ambienti di simmetria e asimmetria strutturale. Mettere in risalto gli ambienti di asimmetria nella realizzazione di $\langle\mathrm{r}\rangle /<\mathrm{rr}>$ può rivelarsi di grande utilità al professore di italiano a brasiliani 0 viceversa, dato che l'apprendimento dei suoni che ne risulta costituisce, probabilmente, non poca difficoltà. 


\section{REFERÊNCIAS BIBLIOGRÁFICAS}

ALKIMIN, M. G. R. \& GOMES, C. A. Dois fenômenos de supressão em limite de palavra. Ensaios de Lingüística, $\mathrm{n}^{\circ} 7$, Belo Horizonte, 1982.

BATINTI, A. Il sistema fonologico dell'italiano. Perugia: Edizioni Guerra, 1993.

BIAGI, A. M. L. Linguistica essenziale. Milano: Garzanti, 1992.

CÂMARA JR., M. Estrutura da língua portuguesa. Petrópolis: Vozes, 1970.

CANEPARI, L. Italiano standard e pronunce regionali. Padòva: Cleup, 1986.

Manuale di pronuncia italiana. Bologna: Zanichelli, 1992.

DARDANO, M. Manualetto di linguistica italiana. Firenze: Zanichelli, 1991.

ZINGARELLI, N. Il nuovo Zingarelli. Bologna: Zanichelli, 1989. 